\title{
X-ray diffraction, cements and environment, three worlds in one.
}

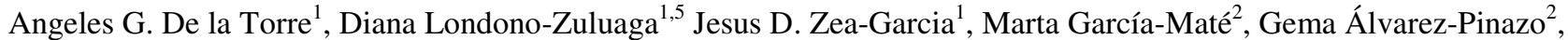 \\ Miguel A. G. Aranda ${ }^{1,3}$, Isabel Santacruz ${ }^{1}$, Ana Cuesta ${ }^{3}$, Laura León-Reina ${ }^{4}$, Francisco Franco ${ }^{1}$, Jorge I. Tobón ${ }^{5}$. \\ ${ }^{1}$ Universidad de Málaga, Departamento de Química Inorgánica, Cristalografía y Mineralogía, Málaga, Spain \\ ${ }^{2}$ X-Ray Data Services S.L., Málaga, Spain. \\ ${ }^{3}$ ALBA Synchrotron, Barcelona, Spain \\ ${ }^{4}$ Universidad de Málaga, Servicios Centrales de Apoyo a la Investigación, Málaga, Spain \\ ${ }^{5}$ Universidad Nacional de Colombia, Grupo del Cemento y Materiales de Construcción, CEMATCO, Medellín, Colombia
}

\begin{abstract}
This keynote lecture will be focused on the strategies for reducing $\mathrm{CO}_{2}$ emissions in the cement production. Concretely, the production of ecocements with optimised formulations that yield reductions in $\mathrm{CO}_{2}$ emissions of up to $25 \%$, when compared to OPC production. Phase assemblage has to be carefully optimised to be competitive and these new ecocements should develop compressive strengths of at least $50 \mathrm{MPa}$ at 28 days of hydration. Optimised compositions of several ecocements will be discussed, but all of them are ye'elimite or calcium sulphoaluminate containing ones: belite-ye'elimite-ferrite (BYF), belite-alite-ye'elimite (BAY) and ye'elimite rich ones (CSA). The clinkering temperature of BYF and BAY has to be established to obtain the targeted phase assemblages. Moreover, the stabilisation of alpha-forms of belite is needed to develop high mechanical strengths at early ages. The benefits of the use of waste materials (such as fly ash or slag) as additions to ecocements are three-fold: lower $\mathrm{CO}_{2}$ emissions due to clinker replacement; valorisation of "useless" products that need a lot of landscape and the consequent efficient consumption of raw materials; and to enhance mechanical properties of the corresponding mortars. The design of appropriate CSA, BYF and BAY mortars, with the final aim of knowing and controlling the hydration mechanisms, will be presented. Particularly, the role of i) type and amount of set regulator (gypsum, anhydrite, etc.), ii) water/cement ratio (w/c); iii) superplasticiser; and iv) pozzolanic additions will be discussed. The role of these parameters in the microstructure and hydraulic behaviour has been investigated through traditional techniques as well as advanced synchrotron characterisation. The formers include laboratory/synchrotron X-ray powder diffraction combined with Rietveld methodology (to obtain phase assemblage), electron microscopy techniques for paste microstructure determination, rheological studies (to control the effect of the different additives, w/c ratio and setting time retarders) and mechanical tests (setting times, compressive strengths and dimensional stability). The latters comprise a group of techniques available at synchrotrons such as: i) high temperature x-ray diffraction for clinkering studies and ii) total scattering data to be analysed by pair distribution function, PDF.
\end{abstract}

\section{Introduction}

Ye'elimite containing-cements are considered as ecocements as less $\mathrm{CO}_{2}$ is released during their production compared to OPC. This is due to the presence of ye'elimite in their composition, which is a low calcitedemanding phase $(0.22 \mathrm{t} / \mathrm{t}$ phase $)$. Other phases present in OPC such as alite $(0.58 \mathrm{t} / \mathrm{tphase})$, belite $(0.51 \mathrm{t} / \mathrm{tphase})$, tricalcium aluminate $(0.49 \mathrm{t} / \mathrm{tphase})$ or calcium aluminate ferrite $(0.22 \mathrm{t} /$ tphase $)$ are high calcite-demanding phases. For this reason, and their high performances, the research on these cements has recently been increased [1]. The mineralogy of these new binders is of great importance to understand and predict final performances of the derived mortars and concretes.
Ye'elimite, also called Klein's salt or tetracalcium trialuminate sulphate $\mathrm{C}_{4} \mathrm{~A}_{3} \hat{\mathrm{S}}$, crystallizes as an orthorhombic phase [2]. Moreover, the presence of foreign ions in the structure stabilizes a pseudo-cubic form [3]. Ye'elimite-containing cements can be gathered in three main groups [1]: i) Calcium Sulpho-Aluminate (CSA), ii) Belite Calcium Sulpho-Aluminate or sulphobelite (BYF, from Belite-Ye'elemite-Ferrite cements) and iii) Belite-Alite-Ye'elimite (BAY) cements.

In the last ten years, research has been ongoing to solve the technological problem of BYF, which is the low mechanical strengths developed at early ages [4-6] by stabilising high-temperature belite polymorphs ( $\alpha$-forms) by the addition of minor elements. Another strategy to active these ye'elimite containing cements is the 
production of a cement with both alite and belite (BAY) [7-9].

The hydration reactions involving ye'elimite have to be fully understood to control and tune-up these type of cements. There is some controversy in the literature data about the hydration behaviour of ye'elimite in absence of other soluble sulphate groups [10-12]. In addition, belite reactivity is important, especially for BYF and BAY cements. Independently on the polymorphism, the hydration behaviour of belite may yield a nanocrystalline C-S-H gel, similar to that arising from the hydration of alite. However, in hydrated BYF systems, belite coexists with a hydrated amorphous aluminate rich environment which favours the formation of an AFm-type phase called stratlingite $[4,13,14]$, which may play an important role in mechanical strengths [15].

\section{Clinkering of BYF and BAY.}

\subsection{Clinkering in-situ Synchrotron X-ray powder diffraction (SXRPD) study of BYF and aBYF.}

Clinkering reactions of BYF and aBYF (active BYF) were studied by in-situ SXRPD. Several reactions were followed including $\alpha_{\mathrm{H}^{-}}^{\prime} \mathrm{C}_{2} \mathrm{~S} \rightarrow \beta-\mathrm{C}_{2} \mathrm{~S}$ polymorphic transformation, the decomposition of ye'elimite and the melting of $\mathrm{C}_{4} \mathrm{AF}$. Overall, these temperatures decrease with the addition of $\mathrm{B}_{2} \mathrm{O}_{3}$ [16]. Figure 1 shows the phase evolution, including the melted phase, for aBYF and a Rietveld plot of this clinker at $1586 \mathrm{~K}$ as an example. The most important results were that i) the $\alpha_{H}^{\prime} \rightarrow \beta$ polymorphic transformation temperature was reduced from $\sim 1650 \mathrm{~K}$ in BYF to $1250 \mathrm{~K}$ in aBYF; ii) the decomposition temperature of ye'elimite was also lowered from $\sim 1550 \mathrm{~K}$ in BYF to $\sim 1500 \mathrm{~K}$ in aBYF. Furthermore, the addition of $\mathrm{B}_{2} \mathrm{O}_{3}$ also decreased the melting temperature of $\mathrm{C}_{4} \mathrm{AF}$ from $\sim 1550 \mathrm{~K}$ to $\sim 1430 \mathrm{~K}$.

\subsection{Clinkering of BYF and BAY: Activation.}

The "medium-scale" synthesis ( 2 kg) of BYF and BAY clinkers was performed by mixing the same raw materials commonly used in cement plants.

The targeted composition of BYF clinker was $\sim 50 \mathrm{wt} \%$ of $\mathrm{C}_{2} \mathrm{~S}, \sim 30 \mathrm{wt} \%$ of $\mathrm{C}_{4} \mathrm{~A}_{3} \hat{\mathrm{S}}$ and $\sim 20 \mathrm{wt} \%$ of $\mathrm{C}_{4} \mathrm{AF}$ and that of BAY clinkers was 25-45 wt $\%$ of $\mathrm{C}_{2} \mathrm{~S}, 30-45 \mathrm{wt} \%$ of $\mathrm{C}_{3} \mathrm{~S}, \sim 20 \mathrm{wt} \%$ of $\mathrm{C}_{4} \mathrm{~A}_{3} \hat{\mathrm{S}}$ and $\sim 5 \mathrm{wt} \%$ of $\mathrm{C}_{4} \mathrm{AF}$. In the case of $\mathrm{BAY}$ clinkers, only $\mathrm{CaF}_{2}$ or $\mathrm{CaF}_{2}$ and $\mathrm{ZnO}$ (BAYZ) were added, to success in the preparation of a clinker with both alite and ye'elimite phases. Moreover, $2.0 \mathrm{wt} \%$ and $0.63 \mathrm{wt} \%$ of $\mathrm{B}_{2} \mathrm{O}_{3}$, added as borax, was used to promote the stabilisation of the high temperature polymorphs of belite, in BYF and BAY, respectively, hereafter $\mathrm{aBYF}$ and $\mathrm{aBAY}$.

In all cases, the raw mixture $(\sim 3 \mathrm{~kg})$ was homogenised for $30 \mathrm{~min}$ in a micro-Deval machine. The resulting mixture was pressed into pellets of about $40 \mathrm{~g}(55 \mathrm{~mm}$ of diameter and $\sim 5 \mathrm{~mm}$ of height) and 6 of these ones were placed in a large $\mathrm{Pt} / \mathrm{Rh}$ crucible. A two-step clinkering process was used for all the clinkers: $900^{\circ} \mathrm{C}$ during 30 min (heating rate of $5{ }^{\circ} \mathrm{C} / \mathrm{min}$ ) and further heated at $1300^{\circ} \mathrm{C}$ for $15 \mathrm{~min}$, followed by a quenching with air flow. Table 1 gives the mineralogical phase assemblage of these clinkers.
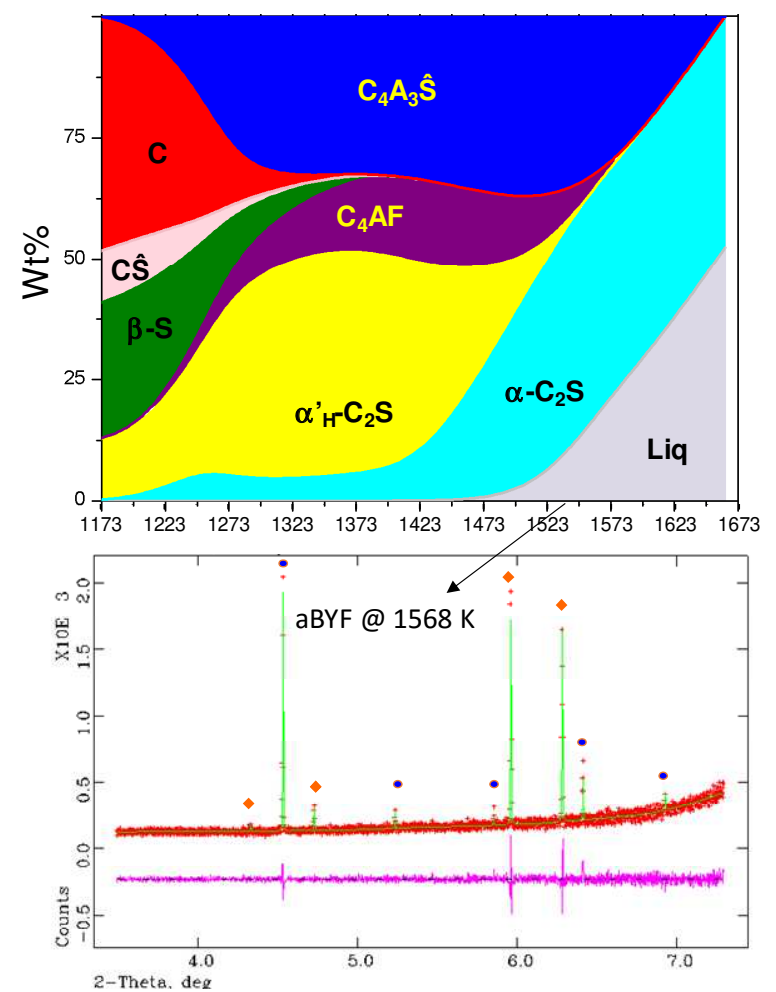

Fig. 1. Normalised phase evolution with temperature aBYF clinkering (top) and Rietveld plot of aBYF at $1568 \mathrm{~K}$ (bottom). Orange rhombus stand for $\alpha-C_{2} S$ and blue circles for ye'elimite.

On the one hand, it is noticeable that the addition of borax to raw mixtures has totally or partially stabilised $\alpha^{\prime}{ }_{\mathrm{H}}-\mathrm{C}_{2} \mathrm{~S}$ and pseudo-cubic ye'elimite. On the other hand, the preparation and scale-up of BAY and BAYZ clinkers with the coexistence of alite and ye'elimite phases [17] by adding $\mathrm{CaF}_{2}$ and $\mathrm{ZnO}$ was a success.

Table 1. Mineralogical phase composition of ye'elimite containing clinkers synthetized at medium scale $(\sim 2 \mathrm{~kg})$ in the laboratory.

\begin{tabular}{|c|c|c|c|c|c|}
\hline Phase & BYF & $\mathbf{a B Y F}$ & BAY & BAYZ & aBAYZ \\
\hline$\alpha^{\prime}{ }_{\mathrm{H}^{-}} \mathrm{C}_{2} \mathrm{~S}$ & - & $57(2)$ & & & 18.1(3) \\
\hline$\beta-\mathrm{C}_{2} \mathrm{~S}$ & $48.7(6)$ & & $59.4(2)$ & $28.4(3)$ & $42.1(2)$ \\
\hline$\gamma-\mathrm{C}_{2} \mathrm{~S}$ & $2.6(5)$ & & $1.2(1)$ & & \\
\hline $\mathrm{C}_{3} \mathrm{~S}$ & & & $14.3(2)$ & $41.5(2)$ & $15.8(2)$ \\
\hline $\mathrm{o}-\mathrm{C}_{4} \mathrm{~A}_{3} \hat{\mathrm{S}}$ & $15(1)$ & & $10.4(1)$ & $9.3(3)$ & $2.9(2)$ \\
\hline $\mathrm{c}-\mathrm{C}_{4} \mathrm{~A}_{3} \hat{\mathrm{S}}$ & $14(1)$ & $31(2)$ & & $8.1(3)$ & $4.8(2)$ \\
\hline $\mathrm{C}_{4} \mathrm{AF}$ & $14.9(2)$ & $10.1(6)$ & $6.5(2)$ & $3.8(1)$ & 3.2 \\
\hline $\begin{array}{l}\text { Minor } \\
\text { phases }\end{array}$ & 5.7 & 2.1 & $5.0(1)$ & $9.0(1)$ & 13.1 \\
\hline
\end{tabular}




\section{Hydration of ye'elimite containing cements: CSA, BYF and BAY.}

\subsection{Role of activation of ye'elimite bearing cements.}

Mortars prepared with aBYF cement developed higher compressive strengths than BYF at any hydration age and BAY at early hydration time (up to 7 days), and higher strengths than BAY at $28 \mathrm{~d}$, Figure 2, independently of the type and amount of sulphate source $[6,18]$.

Standard BYF clinker contains $\beta-\mathrm{C}_{2} \mathrm{~S}$, as main phase and orthorhombic ye'elimite. It has been demonstrated that $\beta$ $\mathrm{C}_{2} \mathrm{~S}$ in these experimental conditions reacts at a higher pace than alpha forms in active BYF [6]to yield stratlingite. This behaviour may well be justified with the formation of high amounts of ettringite at early hours which implies a concomitant large quantity of amorphous aluminium hydroxide. The availability of amorphous $\mathrm{AH}_{3}$ promotes the precipitation of stratlingite, $\mathrm{C}_{2} \mathrm{ASH}_{8}$, from belite reaction. In conclusion, the hydration behaviour of $\mathrm{C}_{2} \mathrm{~S}$ is likely more dependent on the chemical environment than on its polymorphism. However, it must be underlined that although the phases in BYF react faster than in aBYF, the standard cement develops much smaller compressive strength, Figure 2.

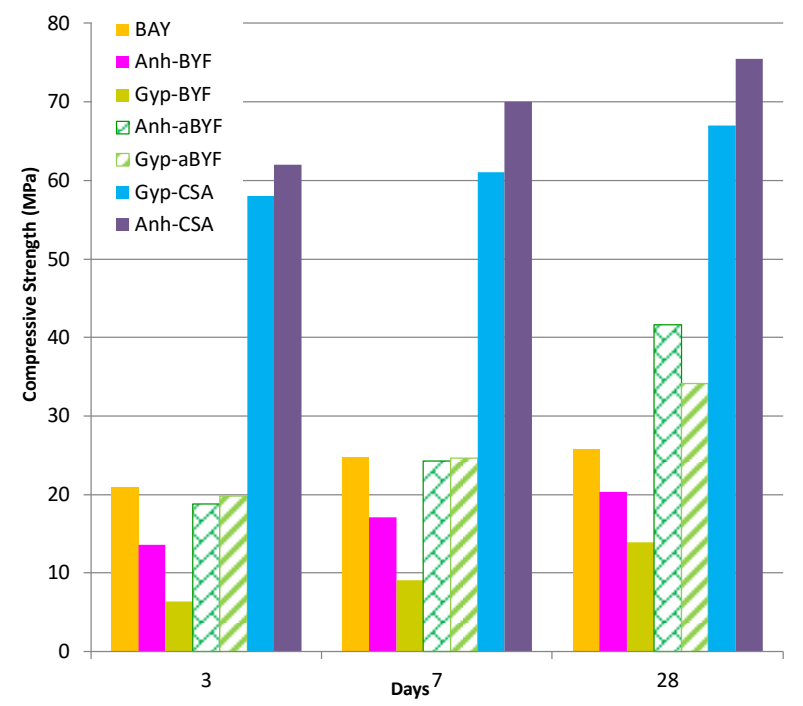

Fig. 2. Compressive strengths of CSA, BYF and BAY mortars.

Furthermore, the activation by synthesising clinkers with alite and ye'elimite, i.e. BAY clinkers, has been a success since BAY mortars show higher compressive strengths than BYF mortars, prepared under similar conditions (anhydrite as setting regulator and $w / c$ ) at any hydration time, Figure 2.

None of BYF or BAY cements have developed higher mechanical strengths than CSA cements, Figure 2. However, CSA cements are more expensive due to the need of high amounts of $\mathrm{Al}_{2} \mathrm{O}_{3}$, mainly as highly pure bauxite. So BYF and BAY are proposed as a suitable cheap environmental solution.

\subsection{Role of type of setting regulator: gypsum, bassanite or anhydrite}

The effect on hydration behaviour and mechanical strengths of three different setting regulators (gypsum, bassanite and anhydrite) has also been studied. The dissolution rate of the different studied sulphate sources is a key point to control the reactions during hydration of CSA and BYF cements, and hence the mechanical properties of the corresponding pastes and mortars.

The dissolution of anhydrite is the slowest of the three sulphate sources. Cements and mortars prepared with anhydrite, showed higher initial setting times than those prepared with gypsum. Consequently, mechanical strengths after 3 days of hydration, Figure 2, are lower than those of mortars prepared with CSA or BYF with gypsum. However, these longer setting times of anhydrite pastes provides them with high plasticity to accommodate the precipitation of ettringite at later ages, and thus mortars showed similar compressive strength values Figure 2.

CSA or BYF with bassanite pastes showed high water demand, high viscosity values and short setting times with the consequent dramatic effect on the mechanical strength values of the corresponding mortars. This makes necessary the selection of a hydration retarder which also reduces the viscosity of the pastes [18,19], Figure 2.

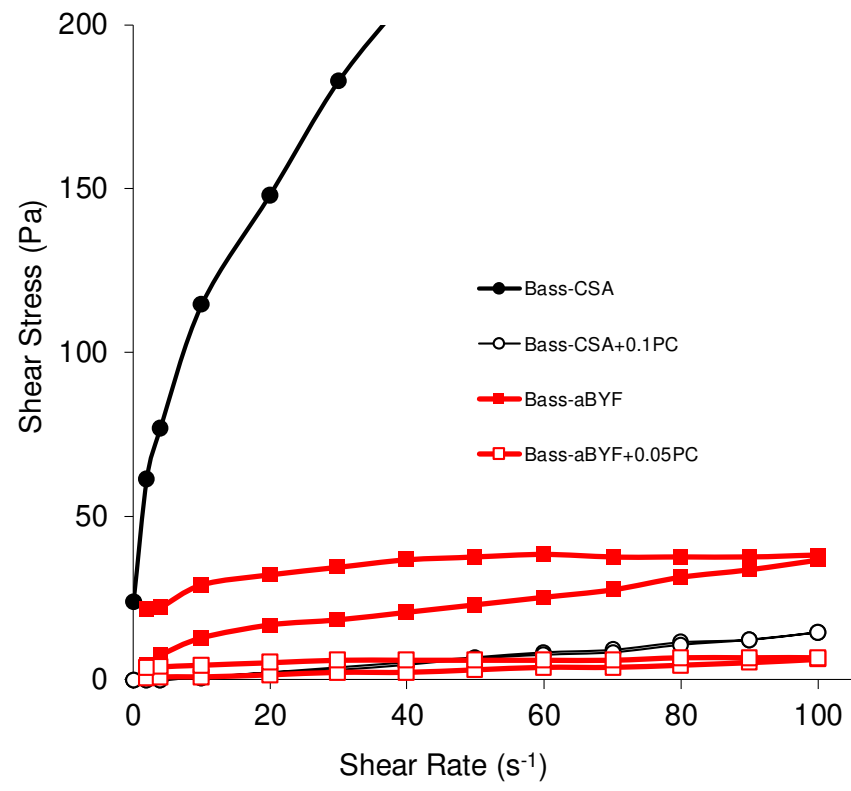

Fig. 3. Flow curves of CSA and aBYF pastes prepared with bassanite as setting regulator without and with (open symbols) a superplasticizer/retarder based on polycarboxylate.

The effect of three additives (polycarboxylate, tartaric acid and phosphonic acid) on CSA pastes and mortars was studied [20]. The amount of each additive was optimised elsewhere [20] and all of them improved the workability of pastes, where the polycarboxylate (PC) was the best additive in reducing viscosity at very early ages. All these parameters could be controlled, making possible the design and preparation of mortars with selected properties for specific engineering applications 
[20]. Figure 3 shows the flow curves of aBYF and CSA pastes prepared with bassanite without and with a small amount of PC.

\section{Hydration of pure phases related to CSA, BYF and BAY.}

\subsection{Hydration of ye'elimite.}

The crystal structures of orthorhombic ye'elimite [2] and pseudo-cubic ye'elimite [3] were studied. Moreover, the hydration behaviour of both polymorphs with or without sulphate source was studied [21]. These studies unravelled that hydration kinetics of ye'elimite samples not only depends on the water/solid (w/s) ratio and the solubility of the additional sulphate source, but also on the polymorphism of ye'elimite. Firstly, in the absence of additional sulphate sources, orthorhombic ye'elimite reacts slower than pseudo-cubic ye'elimite and the latter produces higher amounts of ettringite than orthorhombic ye'elimite in similar hydrating conditions. Moreover, in this environment, the formation of AFm-type phases from orthorhombic ye'elimite is strongly accelerated and favoured by high w/s ratios. Moreover, in presence of gypsum or anhydrite as additional sulphate sources, orthorhombic ye'elimite reacts faster than pseudo-cubic ye'elimite. In addition, the formation of AFm-type phases at late ages is avoided by the addition of gypsum and anhydrite being ettringite the only crystalline phase formed in this reaction medium.

Furthermore, the particle size [22], water content and the calcium uptake of amorphous aluminium hydroxide gels in ye'elimite eco-cements have been established with $\mathrm{Ca}$ contents being minor but not negligible [23].

\subsection{Hydration of ye'elimite with ferrite.}

The jointly hydration of ye'elimite and ferrite was also studied [24]. The hydration of a sample with ferrite, gypsum and orthorhombic ye'elimite gives a mixture of $\mathrm{AFt}$ and $\mathrm{AFm}$ phases. However, $\mathrm{C}_{4} \mathrm{AF}$ hydration is slightly slowed down and moreover, these hydration products did not contain iron in their structures. The retarder effect of ye'elimite over $\mathrm{C}_{4} \mathrm{AF}$ hydration was much stronger with pseudo-cubic ye'elimite and consequently AFt was the main hydration phase.

$\mathrm{C}_{4} \mathrm{AF}$ was hydrated with ye'elimite in the absence of gypsum and gave AFm as the unique hydration product, Figure 4. Consequently, it was demonstrated that gypsum (which is a high soluble sulphate) was the main responsible for AFt formation in these systems.

\subsection{Hydration of ye'elimite with belite and alite.}

The reactivity of ye'elimite in the presence of both dicalcium silicate and alite has also been studied. Both polymorphs, $\alpha_{H}^{\prime}$ and $\beta$ of dicalcium silicate were synthesized $[25,26]$ and mixed jointly with both ye'elimites and gypsum. Moreover, mixtures of aliteye'elimites and anhydrite were also prepared. The mixtures were hydrated. Table 2 gives the mineralogical composition, including amorphous contents (ACn) and free water $(\mathrm{FW})$ of mixtures after 28 days of hydration of mixtures of $\mathrm{C}_{2} \mathrm{~S}$ and ye'elimite with gypsum. In these experimental conditions the presence of belite in the mixture has not altered the hydration kinetics of ye'elimite. Pseudo-cubic ye'elimite (with a Dv50 of $5 \mu \mathrm{m}$ ) reacts at a higher pace than orthorhombic (with a Dv50 of $9 \mu \mathrm{m}$ ) yielding higher amounts of AFt, Table 2. This last conclusion is also extensible to the mixtures containing alite.

Moreover, we have demonstrated that the hydration degree of $\alpha_{\mathrm{H}^{-}}^{\prime} \mathrm{C}_{2} \mathrm{~S}$ is much larger than that of $\beta-\mathrm{C}_{2} \mathrm{~S}$.

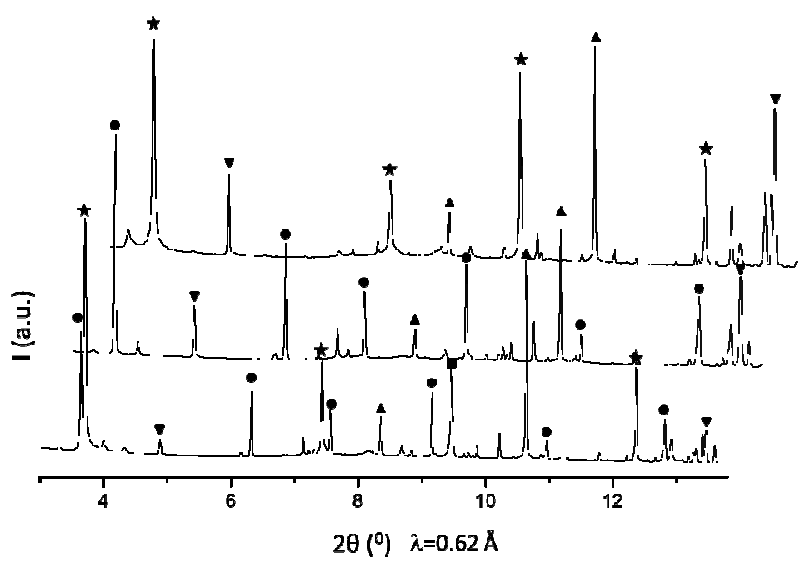

Fig. 4. SXRPD patterns of mixtures of (bottom) orthorhombic ye'elimite/ferrite/gypsum, (medium) pseudocubic ye'elimite/ferrite/gypsum and (top) orthorhombic ye'elimite/ferrite after $\sim 20$ hours of hydration. AFt: circle, AFm: star, Quartz: triangle; ye'elimite: square; $\mathrm{C}_{4} \mathrm{AF}$ : inverted triangle.

Table 2. Quantitative phase analysis results (wt\%) of mixtures of orthorhombic or pseudo-cubic ye'elimite $\left(\mathrm{o}-\mathrm{C}_{4} \mathrm{~A}_{3} \hat{\mathrm{S}}\right.$ or c$\left.\mathrm{C}_{4} \mathrm{~A}_{3} \hat{\mathrm{S}}\right), \boldsymbol{\beta}-\mathbf{C}_{\mathbf{2}} \mathbf{S}$ or $\boldsymbol{\alpha}_{\mathbf{H}^{-}}^{\prime} \mathbf{C}_{\mathbf{2}} \mathbf{S}$ with gypsum after 28 days of hydration obtained from LXRPD.

\begin{tabular}{|c|c|c|c|c|}
\hline & $\begin{array}{c}\beta-\mathrm{C}_{2} \mathrm{~S}- \\
\text { o- } \mathrm{C}_{4} \mathrm{~A}_{3} \hat{\mathrm{S}}\end{array}$ & $\begin{array}{l}\alpha^{\prime}{ }_{\mathrm{H}^{-}} \mathrm{C}_{2} \mathrm{~S} \\
\mathrm{o}-\mathrm{C}_{4} \mathrm{~A}_{3} \hat{\mathrm{S}}\end{array}$ & $\begin{array}{c}-\mathrm{C}_{2} \mathrm{~S}- \\
\mathrm{c}-\mathrm{C}_{4} \mathrm{~A}_{3} \hat{\mathrm{S}}\end{array}$ & $\begin{array}{l}\alpha_{H^{-}-C_{2} S}^{\prime S} \\
c-C_{4} A_{3} \hat{S}\end{array}$ \\
\hline $\mathrm{C}_{4} \mathbf{A}_{3} \hat{S}$ & $0.9(1)$ & $2.6(1)$ & - & - \\
\hline$\alpha_{\mathrm{H}^{\prime}}^{\prime}-\mathrm{C}_{2} \mathrm{~S}$ & - & $13.9(4)$ & - & $11.8(4)$ \\
\hline$\beta-C_{2} S$ & $20.6(2)$ & $9.3(3)$ & $20.1(2)$ & $9.8(3)$ \\
\hline Strat & $6.5(3)$ & $6.4(3)$ & $6.7(2)$ & $10.2(3)$ \\
\hline AFt & 21.1(2) & 19.9(2) & $23.5(2)$ & $23.3(2)$ \\
\hline Gib & $0.5(1)$ & $0.5(1)$ & $0.5(1)$ & $0.4(1)$ \\
\hline $\mathbf{A C n}$ & $33.0(5)$ & $31.8(6)$ & $32.9(4)$ & $32.7(6)$ \\
\hline FW & 15.1 & 14.9 & 14.3 & 11.8 \\
\hline
\end{tabular}

\section{Acknowledgements}

PhD D. Londono-Zuluaga thanks Colciencias and Enlaza Mundos program $\mathrm{PhD}$ grant. Spanish MINECO (BIA2014-57658-C2-2-R, which is co-funded by FEDER, BIA2014-57658-C2-1-R and I3 (IEDI-20160079) grants) are acknowledged.

\section{References}

[1] M.A.G. Aranda, A.G. De la Torre, 18 - 
Sulfoaluminate cement, in: Eco-Efficient Concr., 2013: $\quad$ pp. 488-522. doi:10.1533/9780857098993.4.488.

[2] A. Cuesta, A.G. De La Torre, E.R. Losilla, V.K. Peterson, P. Rejmak, A. Ayuela, C. Frontera, M.A.G. Aranda, Structure, atomistic simulations, and phase transition of stoichiometric yeelimite, Chem. Mater. 25 (2013) 1680-1687. doi: $10.1021 / \mathrm{cm} 400129 \mathrm{z}$.

[3] A. Cuesta, Á.G. De La Torre, E.R. Losilla, I. Santacruz, M.A.G. Aranda, Pseudocubic crystal structure and phase transition in doped ye' elimite, Cryst. Growth Des. 14 (2014) 5158-5163. doi:10.1021/cg501290q.

[4] G.S. Li, E. Gartner, High-belite sulfoaluminate clinker: fabrication process and binder preparation, French patent application 04-51586 (publication 2873366), 2006.

[5] A.J.M. Cuberos, A.G. De La Torre, G. AlvarezPinazo, M.C. Martín-Sedeño, K. Schollbach, H. Pöllmann, M.A.G. Aranda, Active iron-rich belite sulfoaluminate cements: clinkering and hydration., Environ. Sci. Technol. 44 (2010) 6855-6862.

[6] G. Álvarez-Pinazo, I. Santacruz, L. León-Reina, M.A.G. Aranda, A.G. De la Torre, Hydration Reactions and Mechanical Strength Developments of Iron-Rich Sulfobelite Ecocements, Ind. Eng. Chem. Res. 52 (2013) 1660616614. doi:10.1021/ie402484e.

[7] N. Chitvoranund, B. Lothenbach, F. Winnefeld, C.W. Hargis, Synthesis and hydration of alitecalcium sulfoaluminate cement, Adv. Cem. Res. (2016).

[8] Y. Hu, S. Ma, W. Li, X. Shen, The Preparation and Composition Analysis of Alite-Ye'Elimite With Industrial Wastes, Ceram. - Silikaty. 60 (2016) 1-10. doi:10.13168/cs.2016.0027.

[9] S. Ma, R. Snellings, X. Li, X. Shen, K.L. Scrivener, Alite-ye'elimite cement: Synthesis and mineralogical analysis, Cem. Concr. Res. 45 (2013)

15-20. doi:10.1016/j.cemconres.2012.10.020.

[10] F. Winnefeld, S. Barlag, Calorimetric and thermogravimetric study on the influence of calcium sulfate on the hydration of ye ' elimite, J. Therm. Anal. Calorim. 101 (2010) 949-957. doi:10.1007/s10973-009-0582-6.

[11] F. Song, Z. Yu, F. Yang, Y. Lu, Y. Liu, Microstructure of amorphous aluminum hydroxide in belite-calcium sulfoaluminate cement, Cem. Concr. Res. 71 (2015) 1-6. doi:10.1016/j.cemconres.2015.01.013.

[12] A. Telesca, M. Marroccoli, M.L. Pace, M. Tomasulo, G.L. Valenti, P.J.M. Monteiro, A hydration study of various calcium sulfoaluminate cements, Cem. Concr. Compos. 53 (2014) 224-232. doi:10.1016/j.cemconcomp.2014.07.002.

[13] K. Scrivener, R. Snellings, B. Lothenbach, A Practical Guide to Microstructural Analysis of Cementitious Materials, CRC Press, Boca Raton,
FL, 2016.

[14] B. Lothenbach, K. Scrivener, R.D. Hooton, Supplementary cementitious materials, Cem. Concr. Res. 41 (2011) 1244-1256. doi:10.1016/j.cemconres.2010.12.001.

[15] I. Mehdipour, A. Kumar, K.H. Khayat, Rheology, hydration, and strength evolution of interground limestone cement containing PCE dispersant and high volume supplementary cementitious materials, Mater. Des. 127 (2017) 54-66. doi:10.1016/j.matdes.2017.04.061.

[16] Á.G. De La Torre, A.J.M. Cuberos, G. ÁlvarezPinazo, A. Cuesta, M.A.G. Aranda, In situ powder diffraction study of belite sulfoaluminate clinkering, J. Synchrotron Radiat. 18 (2011) 506514.

[17] D. Londono-Zuluaga, J.I. Tobon, M.A.G. Aranda, I. Santacruz, A.G. De La Torre, Clinkering and hydration of Belite-AliteYéelimite cement, Cem. Concr. Compos. 80 (2017) $333-341$. doi:10.1016/j.cemconcomp.2017.04.002.

[18] G. Álvarez-pinazo, I. Santacruz, Hydration of belite - ye'elimite - ferrite cements with different calcium sulfate sources, Adv. Cem. Res. 28 (2016) 529-543. doi:10.1680/jadcr.16.00030.

[19] M. García-Maté, A.G. De La Torre, L. LeónReina, E.R. Losilla, M.A.G. Aranda, I. Santacruz, Effect of calcium sulfate source on the hydration of calcium sulfoaluminate eco-cement, Cem. Concr. Compos. 55 (2015) 53-61. doi:10.1016/j.cemconcomp.2014.08.003.

[20] M. García-Maté, D. Londono-Zuluaga, A.G. De la Torre, E.R. Losilla, A. Cabeza, M.A.G. Aranda, I. Santacruz, Tailored setting times with high compressive strengths in bassanite calcium sulfoaluminate eco-cements, Cem. Concr. Compos. $72 \quad$ (2016) 39-47. doi:10.1016/j.cemconcomp.2016.05.021.

[21] A. Cuesta, G. Álvarez-Pinazo, S.G. Sanfélix, I. Peral, M.A.G. Aranda, A.G. De la Torre, Hydration mechanisms of two polymorphs of synthetic ye'elimite, Cem. Concr. Res. 63 (2014) 127-136. doi:10.1016/j.cemconres.2014.05.010.

[22] A. Cuesta, R.U. Ichikawa, D. Londono-Zuluaga, A.G. De la Torre, I. Santacruz, X. Turrillas, M.A.G. Aranda, Aluminum hydroxide gel characterization within a calcium aluminate cement paste by combined Pair Distribution Function and Rietveld analyses, Cem. Concr. Res. $\quad 96 \quad$ (2017) $1-12$. doi:10.1016/j.cemconres.2017.02.025.

[23] A. Cuesta, A.G. De la Torre, I. Santacruz, P. Trtik, J.C. da Silva, A. Diaz, M. Holler, M.A.G. Aranda, Chemistry and Mass Density of Aluminum Hydroxide Gel in Eco-Cements by Ptychographic X-ray Computed Tomography, J. Phys. Chem. C. 121 (2017) 3044-3054. doi:10.1021/acs.jpcc.6b10048.

[24] A. Cuesta, I. Santacruz, S.G. Sanfélix, F. Fauth, M.A.G. Aranda, A.G. De la Torre, Hydration of $\mathrm{C} 4 \mathrm{AF}$ in the presence of other phases: A 
synchrotron X-ray powder diffraction study, Constr. Build. Mater. 101 (2015) 818-827. doi:10.1016/j.conbuildmat.2015.10.114.

[25] A. Cuesta, E.R. Losilla, M.A.G. Aranda, J. Sanz, Á.G. De La Torre, Reactive belite stabilization mechanisms by boron-bearing dopants, Cem. Concr. Res. 42 (2012) 598-606.

[26] A. Cuesta, M.A.G. Aranda, J. Sanz, Á.G. de la Torre, E.R. Losilla, R. Kastanet, L. León-Reina, M.A.G. Aranda, Mechanism of stabilization of dicalcium silicate solid solution with aluminium, Dalt. Trans. 43 (2014) 2176-2182. doi:10.1039/C3DT52194J. 